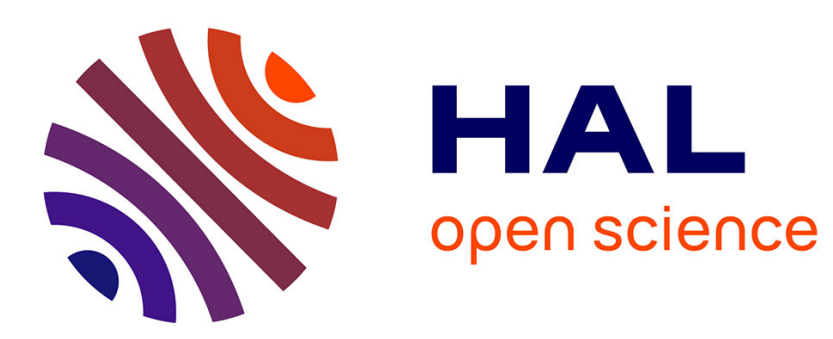

\title{
Experimental monitoring data for prognostics and health management of MEMS
}

Haithem Skima, Kamal Medjaher, Christophe Varnier, Noureddine Zerhouni

\section{To cite this version:}

Haithem Skima, Kamal Medjaher, Christophe Varnier, Noureddine Zerhouni. Experimental monitoring data for prognostics and health management of MEMS. CoDIT 2017, 4th InternationaConference on Control, Decision and Information Technologies, Apr 2017, Barcelona, Spain. pp.0. hal-01977347

\section{HAL Id: hal-01977347 \\ https://hal.science/hal-01977347}

Submitted on 10 Jan 2019

HAL is a multi-disciplinary open access archive for the deposit and dissemination of scientific research documents, whether they are published or not. The documents may come from teaching and research institutions in France or abroad, or from public or private research centers.
L'archive ouverte pluridisciplinaire HAL, est destinée au dépôt et à la diffusion de documents scientifiques de niveau recherche, publiés ou non, émanant des établissements d'enseignement et de recherche français ou étrangers, des laboratoires publics ou privés. 


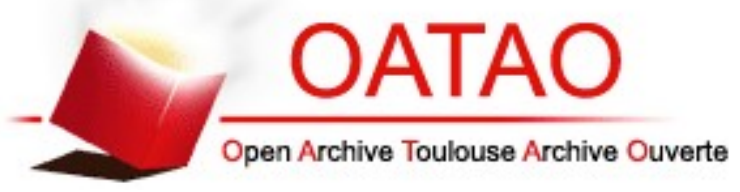

\section{Open Archive Toulouse Archive Ouverte (OATAO)}

OATAO is an open access repository that collects the work of Toulouse researchers and makes it freely available over the web where possible.

This is an author-deposited version published in: http://oatao.univ-toulouse.fr/ Eprints ID: 18696

\section{To cite this version:}

Skima, Haithem and Medjaher, Kamal and Varnier, Christophe and Zerhouni, Noureddine Experimental monitoring data for prognostics and health management of MEMS. (2017) In: CoDIT 2017, 4th InternationaConference on Control, Decision and Information Technologies, 5 April 2017 - 7 April 2017 (Barcelona, Spain). 


\title{
Experimental Monitoring Data for Prognostics and Health Management of MEMS
}

\author{
Haithem Skima, Kamal Medjaher, Christophe Varnier, and Noureddine Zerhouni
}

\begin{abstract}
This paper presents the data acquisition step of a Prognostics and Health Management (PHM) of Micro-ElectroMechanical Systems (MEMS) application. The targeted MEMS device is an electro-thermally actuated MEMS valve. The data acquisition is performed during the accelerated lifetime tests. To perform tests, an experimental test bed is designed and built. Several test campaigns are performed where MEMS valves operated continuously and data acquired regularly. The obtained experimental results show that MEMS fabricated with the same micro-fabrication process and tested in the same conditions do not have the same behavior and the same evolution of degradation in time. Therefore, this supports the importance of applying PHM of MEMS rather than the predictive reliability.
\end{abstract}

Index Terms-Prognostics and Health Management, MicroElectro-Mechanical Systems, Accelerated Lifetime Tests, Data Acquisition, Fault Detection.

\section{INTRODUCTION}

$\mathbf{T}$ HE miniaturization of systems becomes a challenge in many industrial segments. It allows reducing the occupied space, the weight, the prices and the consumption of energy and material. In the automotive, aerospace, medical, telecommunication and even military applications, systems and equipment perform functions in a more and more reduced volume. For example, the size of satellites is reduce and we talk today about micro-satellites (Fig. 1). Also, mobile phones became smaller with more features. This miniaturization is became possible thanks to the use of Micro-Electro-Mechanical Systems (MEMS).

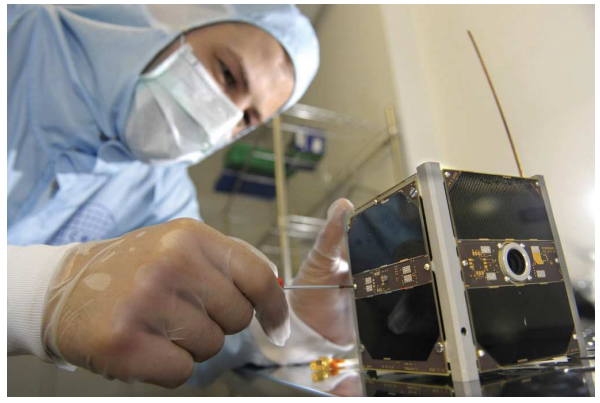

Fig. 1. Micro-satellite swisscube (2009) [1].

MEMS devices are increasingly used in the industrial systems, where they contribute to achieve important functions in

H. Skima, C. Varnier, \& N. Zerhouni are with Institut FEMT-ST UMR 6174, ENS2M, CNRS, Univ. Bourgogne Franche-Comté, F-25000 Besançon, France. e-mail: firstname.lastname@femto-st.fr

K. Medjaher is with Production Engineering Laboratory (LGP), INP-ENIT, F-65016 Tarbes, France. e-mail: kamal.medjaher@enit.fr. sensing, actuating and controlling. However, the complexity of these miniature devices increases the risk of their failure, which can have a negative impact on the availability and the reliability of systems in which they are used. Therefore, it is necessary to continuously monitor these micro-systems to detect degradation as it occurs, monitor its evolution in time and act effectively before that a failure can happen to avoid undesirable situations, which can be catastrophic on the human, economic and environmental levels. To do that, it is important to implement a scientific approach involving various tasks such as data acquisition, monitoring, modeling, analysis and decision making. These tasks are part of the Prognostics and Health Management (PHM) process.

PHM is the combination of seven layers that collectively enable linking failure mechanisms with life management (Fig. 2).

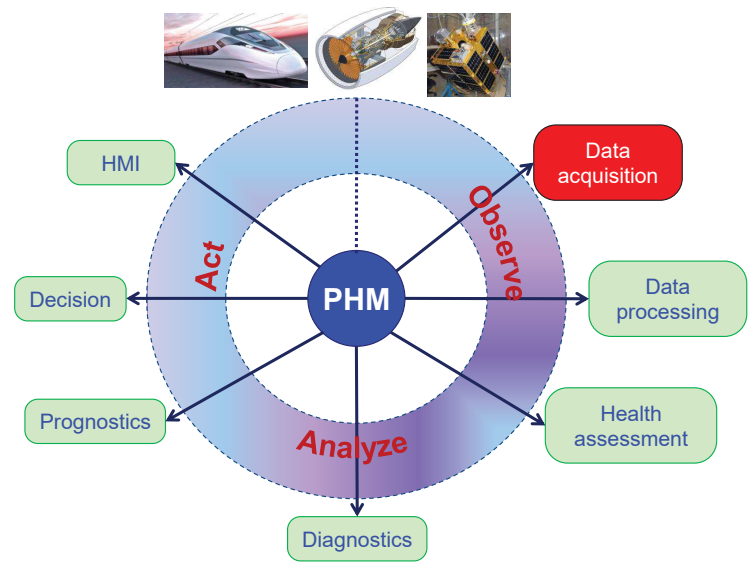

Fig. 2. Prognostics and Health Management cycle [2].

It is a discipline that deals with the study of failure mechanisms in order to extend the life cycle of systems and to better manage their health [3].

Within the framework of PHM, only the step of data acquisition is considered in this paper. This first step aims to collect monitoring data on critical system components. The collected data are needed to monitor the system health state and understand its degradation phenomena. Once the monitoring data are collected, they have to be processed and used for health assessment, diagnostics and prognostics. In the case of MEMS devices, and contrary to macro-systems, this step is complicated to perform given the small size and the complexity of these micro-systems.

In this paper, the data acquisition part of a PHM of MEMS application is presented. The rest of the paper is structured as 
follows. Section II presents the specificities of MEMS devices. The considered MEMS device is presented in Section III. The experimental test bed built to perform accelerated lifetime tests and data acquisition is introduced in Section IV. Section V presents the applied accelerated lifetime test. The different tests, results and discussion are given in Section VI. Finally, conclusions are drawn in Section VII.

\section{MEMS DEVICES SPECIFICITIES}

The problematics of the PHM of MEMS remain the same as in the macro-systems. However, to develop the PHM of MEMS, there are four main specificities that must be taken into account:

1) the difficulty of modeling the MEMS and its degradation.

2) the difficulty of monitoring data acquisition.

3) the difficulty of performing accelerated lifetime tests.

4) the variability in the collected monitoring data.

Modeling a MEMS and its degradation is a task that is not easy to perform. In addition to their micro-metric size, MEMS are multi-physical and complex systems. Thus, its modeling requires a thorough study of their operation, their failure mechanisms, and their environmental factors that may influence the occurrence of degradation.

Concerning the monitoring data acquisition, and in contrary to macro-systems where the installation of monitoring instruments and data acquisition is possible, direct access by sensors can be difficult or sometimes impossible. Indeed, MEMS are often packaged and access to parts that are the cause of failure is, in most of time, very difficult. It is the case for example of the accelerometers, designed by Analog Devices and ST Microelectronics, used in several applications such as cars to trigger the airbag, computers, smart phones, etc. These accelerometers MEMS are packaged so that it is impossible to access its electrostatic actuator, which is the part that usually suffers from degradation. Then, monitor this kind of MEMS is a task that is not feasible. In the PHM context, the challenge is to find techniques and instruments allowing to capture and collect monitoring data.

The third specificity is related to performing accelerated lifetime tests. In order to carry out tests, a MEMS must be fixed in a configuration that meet its standard utilization and adapted to the data acquisition instruments. Therefore, this requires the design and manufacture of special supports.

The last specificity is related to the variability of the collected monitoring data. This variability is due to the sensitivity of MEMS to the conditions of utilization or to the microfabrication process, which are not always accurate and can lead to different behavior of MEMS fabricated with the same micro-fabrication process. These two aspects lead then to the variability in the monitoring data.

\section{CONSIDERED MEMS DEVICE}

The considered MEMS device, presented in Fig 3(a), consists of an electro-thermally actuated MEMS valve of DunAn Microstaq, Inc. (DMQ), company [4]. This valve is designed to control flow rates or pressure with high precision at ultrafast response time (about $50 \mathrm{~ms}$ ). It is currently being used in a number of applications in air conditioning and refrigeration, hydraulic control and air pressure control.

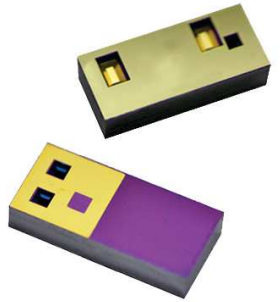

(a)

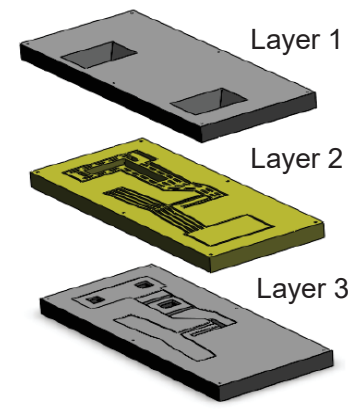

(b)
Fig. 3. (a) The MEMS valve [4] and (b) exploded view of the MEMS valve showing its three silicon layers.

The MEMS valve is composed of three silicon layers (Fig. 3(b)). The center layer (layer 2) contains a movable membrane and an electro-thermal actuator. The other two layer act as interface plates to either electrical connections (layer 1) or fluid connection ports (layer 3) : common port, normally open and normally closed.

By applying a voltage to the valve, the electro-thermal actuator present in the center layer pushes the membrane. This latter is visible through the fluid connection ports (Fig. 4). The movement of the membrane, which depends on the applied voltage, opens (at the normally closed port) or closes (at the normally open port) the air output. The maximum actuation voltage of the valve is $12 \mathrm{~V}$. At $0 \mathrm{~V}$ the air output is closed at normally closed port and open at the normally open port. By increasing the input voltage, the air output starts opening at the normally closed port and closing at the normally open port. Fig. 5 shows the evolution of the displacement of the membrane as a function of the input voltage (from 0 to $12 \mathrm{~V}$ ). Thus, the air pressure at the output depends of the displacement of the membrane.

More details about the MEMS valve can be found in the website of Microstaq company.

\section{EXPERIMENTAL TEST BED}

Studying the behavior of the MEMS valve and understanding its degradation phenomena require reliable monitoring data. For this, an experimental test bed is developed to perform accelerated lifetime tests for the MEMS valve and acquire monitoring data (Fig. 6). Collected data can then be used for the other steps of PHM. As mentioned before, only the data acquisition step is considered in this paper.

Before developing the experimental test bed, two major issues that must be resolved are identified. The first issue concerns the parameters to monitor and the instruments to use. The second issue concerns the technique with which we set this miniature valve so that we can measure the different parameters and perform accelerated lifetime tests.

First, the first issue is addressed. MEMS are miniature devices which are often packaged. This makes access to parts that suffer from degradation a very difficult task to achieve. 


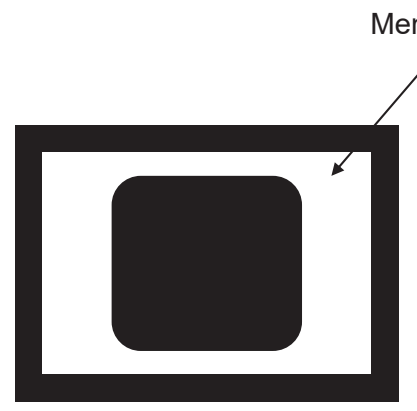

Normally closed

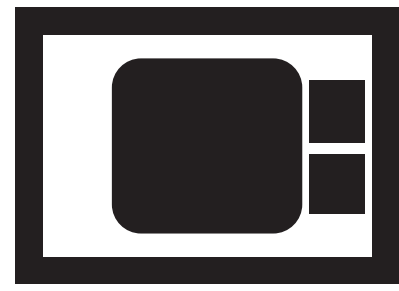

Common port

(the membrane does not move)

Fig. 4. Illustration of the different fluid ports of the MEMS valve.

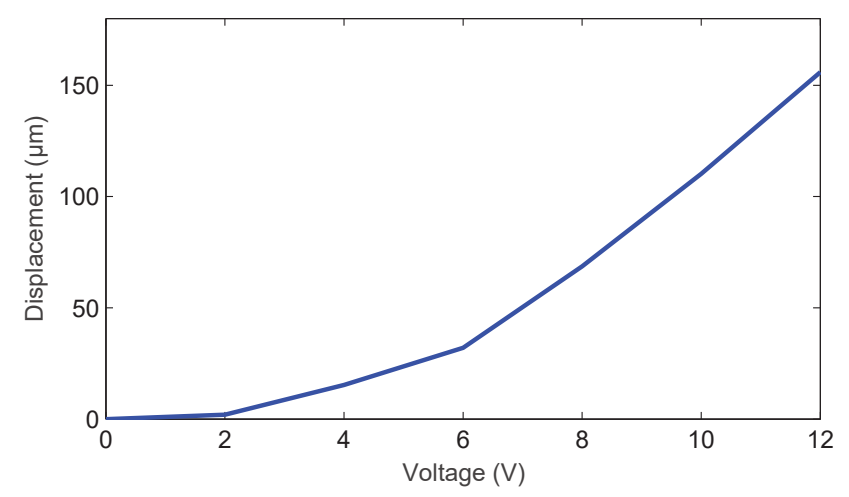

Fig. 5. Displacement of the membrane as a function of the input voltage.

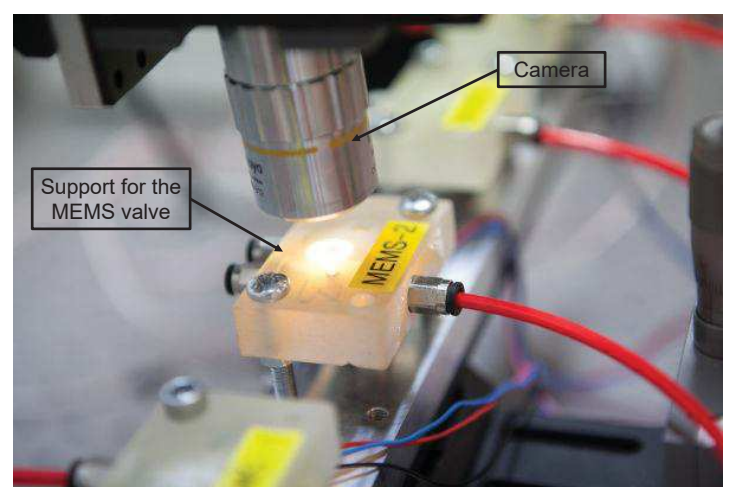

Fig. 6. MEMS valve adjusted under the camera.
This is the case for our MEMS valve, where the electrothermal actuator that moves the membrane is not visible. Only some parts of the membrane are visible through the fluid connection ports. Thus, it is possible to monitor the degradation of the actuator indirectly by monitoring the displacement of the membrane. To do that, a camera that allows to capture images of the membrane through the fluid ports of the valve can be used. By using an image processing algorithm, it is possible to measure the displacement of the membrane.

In order to perform accelerated lifetime tests for the MEMS valve and measure the displacement of it membrane, it is necessary to fix it in a situation which corresponds to its standard utilization. Instead, set a miniature valve with outputs and inputs of air is not an easy task to perform. To solve this problem, we developed a support that can meet our needs.

More details about the experimental test bed can be found in our previous work [3].

\section{ACCELERATED LIFETIME TESTS}

Usually, MEMS devices perform millions of cycles before deteriorating. This makes the estimation of their lifespan under normal operation conditions very difficult to achieve. To do that, performing accelerated lifetime tests can be a solution. An accelerated lifetime test is an aging of a product that induces normal failures in a short period of time by applying stress levels much higher than normal ones (strain, stress, voltage, temperature, vibration rate, pressure, etc.) [5]. The main objective is to observe the evolution over time of the product degradation. In our case, this evolution will be processed and used for health assessment and remaining useful life (RUL) estimation.

The operation of the MEMS valve, which is the subject of this study, is based on an electro-thermal actuator. According to [6], the simplest accelerated lifetime test and most often applied to such an actuator is to perform cycling by applying a periodic square signal.

Before performing cycling of the MEMS valve in the experimental test bed, it necessary to choose the magnitude and the frequency of the actuation signal. According to the datasheet of the MEMS valve, the magnitude of the signal varies between 0 and $12 \mathrm{~V}$.

The frequency of the actuation signal is limited by two constraints. The first constraint is related to the actuator cooling time. According to [7], to ensure that an electro-thermal actuator will have the time to cool between two actuations, the frequency of the signal must be less than $600 \mathrm{~Hz}$. Unlike macro-systems, the micrometer-sized actuator enables rapid cooling. The second constraint is related to the technique used to measure the displacement. Indeed, getting enough images between the actuated state and the non actuated state of the actuator requires a frequency that is not too high.

Tests consist then in cycling several MEMS valves continuously $(24 h / 24)$ with a square signal of a magnitude between 0 and $12 \mathrm{~V}$ and low frequency. During a test campaign, four MEMS valves operate under the same conditions: same temperature, same actuation signal, same air pressure and without mechanical noise. 


\section{TESTS, RESULTS AND DISCUSSION}

Applying the PHM for the MEMS valve starts by collecting monitoring data. This requires the realization of several test campaigns to acquire a significant number of exploitable data.

In this work, we have achieved in total four test campaigns. For the first campaign, an actuation signal of a magnitude equal to $8 \mathrm{~V}$ is applied. This signal provides a displacement which is sufficiently large to be observable. Regarding the frequency of this signal, we chose to use a frequency that is equal to $1 \mathrm{~Hz}$. This frequency allows to have enough images to correctly determine the displacement of the membrane. With the camera that we use, it is possible to take around 123 images during one cycle (one period of the signal). In this first campaign, four MEMS valves are tested with unfiltered air (without using the air filter). All valves tested in this campaign had a lifespan that does not exceed 2 million cycles, while the manufacturer guarantees 8 million cycles before degradation. At the end of the campaign, the membranes of the valves were polluted by strange objects (Fig. 7). These objects came from the unfiltered air and caused the contamination at the membrane and the actuator, resulting in a very small displacement $(\sim 13 \mu \mathrm{m})$.

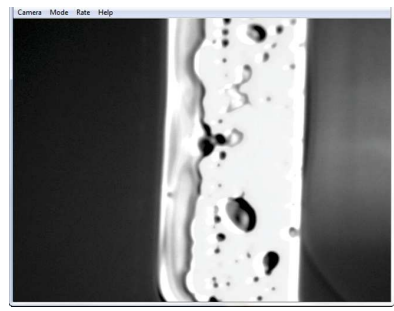

(a)

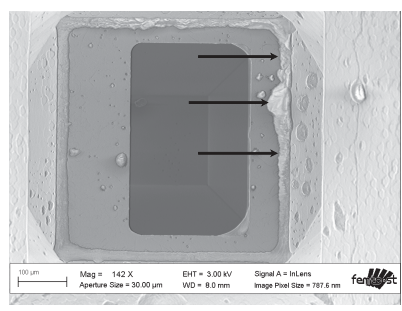

(b)
Fig. 7. (a) Image taken by the camera showing the damaged state of the membrane and (b) SEM image showing the contamination at the normally closed port.

The large quantity of objects inside the valves caused then their premature failures (less than 2 million cycles). The data acquired from this campaign can not therefore be exploited to study the degradation of the MEMS valve. The only conclusion is that we should not operate the valve with unfiltered air.

Note 1: As recommended by the manufacturer of the MEMS valve, a filtered air must be used for the valve. Using unfiltered air leads to abnormal behavior and sudden or premature failures.

In the second campaign, four other MEMS valves are tested, but this time with filtered air. This campaign lasted more than three months, where the MEMS valves operate continuously with the same signal as the previous campaign. During the test, measurements were taken regularly. Fig. 8 shows the evolution of the displacement in time. Despite the MEMS valves are made with the same micro-fabrication process, we noticed that they have different behaviors. Initially at 0 cycles, three MEMS valves (1,2 and 4) have almost the same value of displacement of the membrane (same evolution of the displacement as a function of the input voltage (Fig. 9)). However, the valve 3 has a displacement that is lower than the others. This difference can not be due to testing conditions as all valves operated under the same conditions. It may be due to the non-precision of the micro-fabrication process which is a widespread problem in the field of MEMS. Then, during the accelerated lifetime test, we noticed that the decease in the displacement does not begin at the same time for the four valves. Despite the good state of the membrane, the displacement was very small for all valves at the end of the campaign. Therefore, we decided to stop the test and we considered that the valves are failing. This may be due to a degradation in the actuator. It is difficult to determine exactly the origin of this degradation since we do not have access to the actuator. Probably, it may be due to a fatigue at the actuator arms.

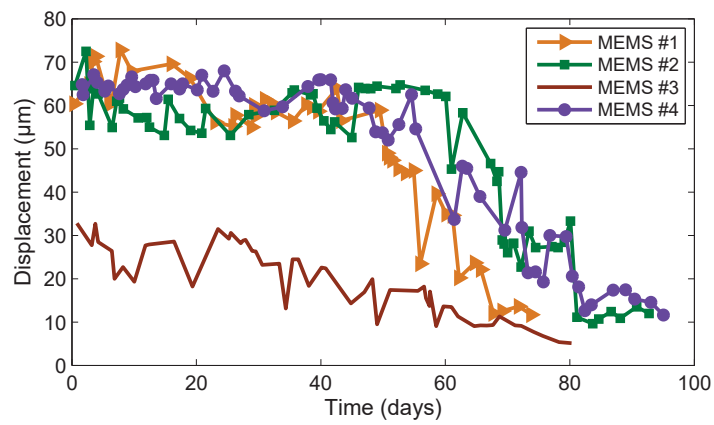

Fig. 8. Experimental results of the second campaign with $8 V$ signal magnitude.

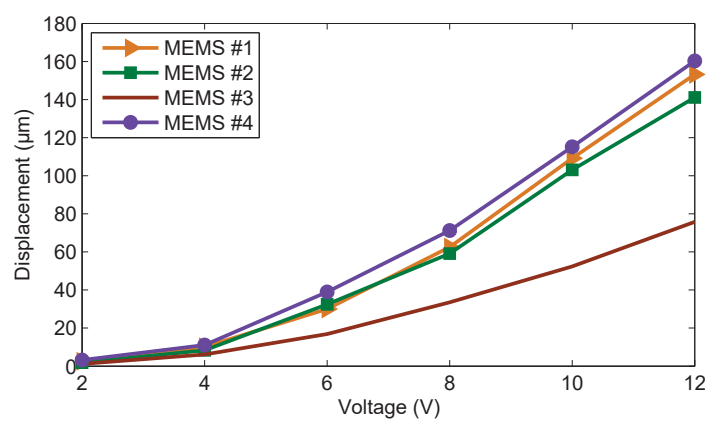

Fig. 9. Evolution of the displacement as a function of the input voltage at 0 cycle (second campaign with $8 \mathrm{~V}$ ).

Note 2: MEMS of the same family and fabricated with the same micro-fabrication process, operating in the same conditions, may not have the same behavior.

Note 3: The degradation of the MEMS valve can be due to a degradation in the actuator. It is difficult to determine the origin of the degradation in a packaged MEMS.

In the third campaign, we decided to increase the magnitude of the actuation signal to the maximum $(12 \mathrm{~V})$ to see how the valve will behave. With a signal of $12 \mathrm{~V}$ magnitude, the current value of the MEMS valve is about $0.7 A$ and its temperature can exceed $90^{\circ} \mathrm{C}$. 
Operating the MEMS valves with a signal of frequency equal to $1 \mathrm{~Hz}$ led to a campaign of test that lasted more than three months. To reduce the time of the testing, we increased the frequency of the actuation signal to $2.5 \mathrm{~Hz}$. With such frequency, the membrane can do its course before returning to its initial position. This means that it makes a complete cycle during a period. However, this frequency does not allow to determine exactly the displacement. For this, we decided to operate the MEMS with a frequency of $2.5 \mathrm{~Hz}$ and change to $1 \mathrm{~Hz}$ when we take the measurements (Figure 10).

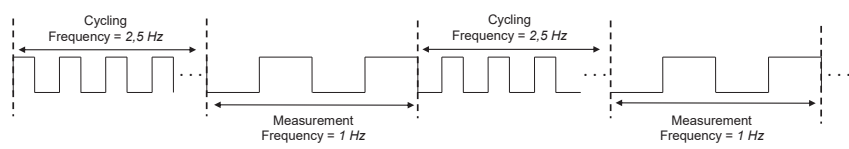

Fig. 10. Changing frequency to cycle and take measures.

The four MEMS valves have operated under the same conditions as the previous campaign. We only changed the actuation signal. The acquisition of data was the same as the previous campaign. Fig. 11 shows the raw results of the evolution of the displacement in time. In this campaign, we noted that all tested valves have different behaviors. At the beginning of the campaign, they have different displacement (Fig. 12). The only explanation for this difference is the nonprecision of the micro-fabrication process. Then, over time, we noticed that the displacement of all MEMS valves decreases, but in different ways and at different times. We can see in Fig. 11 that the displacement of the valve 2 decreases of only $20 \mu \mathrm{m}$. For the other three valves, the decrease of the displacement is more important. With the good state of the membranes of all valves, the same conclusion as the previous campaign can be made. The decrease in the displacement may be due to a fatigue at the actuator arms.

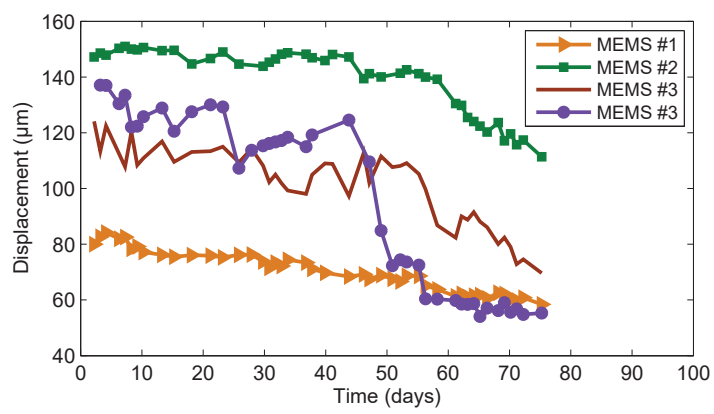

Fig. 11. Experimental results of the first campaign with $12 \mathrm{~V}$ signal magnitude.

In order to evaluate the repeatability of the results, a fourth campaign of test is conducted. All MEMS valves have operated under the same conditions and with the same signal as the previous campaign. Fig. 13 shows that also in this campaign valves have different behaviors. Despite all valves have almost the same value of displacement at the beginning of their life (Fig. 14), the evolution of the displacement in time is different. We noted that the displacement of the valve 4 does not decrease until the end of the campaign (after

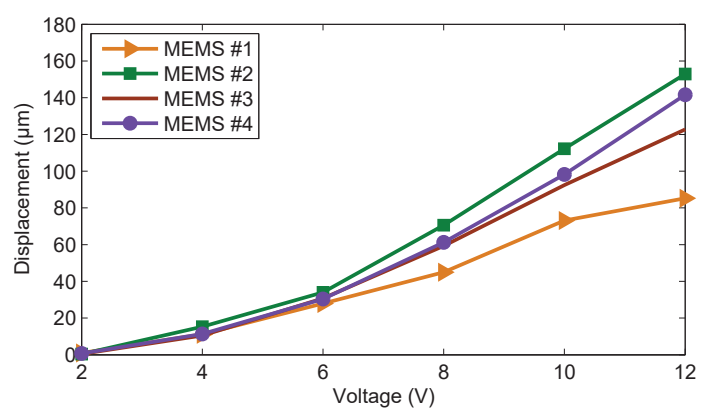

Fig. 12. Evolution of the displacement as a function of the input voltage at 0 cycle (first campaign with $12 \mathrm{~V}$ ).

20 million cycles). However, the displacement of the other valves decreases differently. Same as in other campaigns, the decrease of the displacement may be due to a fatigue at the actuator arms. However, we do not have an explanation of the difference in the decrease of displacement in time.

Note 4: MEMS do not break, but they degrade.

Note 5: The degradation of MEMS fabricated with the same micro-fabrication process does not evolve in the same way. This supports the idea of applying the PHM of MEMS rather than the predictive reliability (see the works of [8] and [9] about the predictive reliability for MEMS devices).

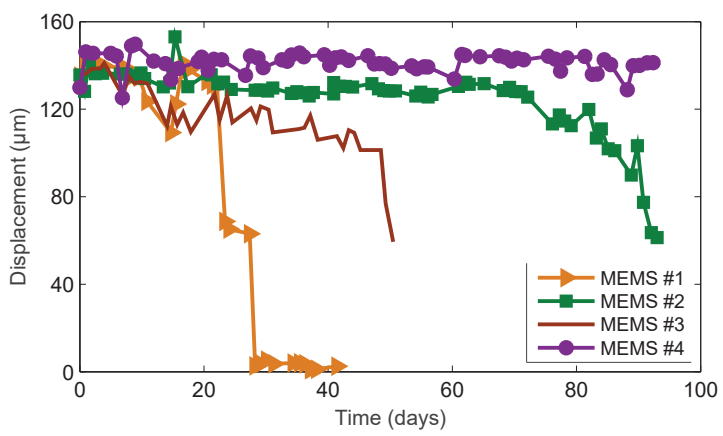

Fig. 13. Experimental results of the second campaign with $12 \mathrm{~V}$ signal magnitude.

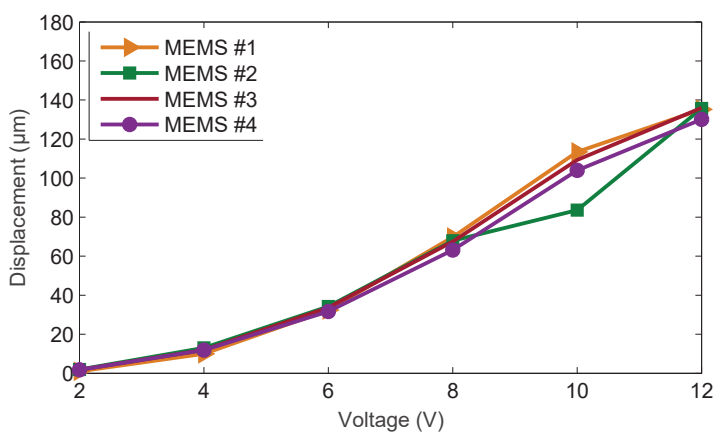

Fig. 14. Evolution of the displacement as a function of the input voltage at 0 cycle (second campaign with $12 \mathrm{~V}$ ). 
TABLE II

VALUES OF THE DISPLACEMENT AT THE BEGINNING AND AT THE END OF THE PERFORMED TEST CAMPAIGNS.

\begin{tabular}{c|c|c|c|c|c}
\multicolumn{2}{l|}{} & MEMS \#1 & MEMS \#2 & MEMS \#3 & MEMS \#4 \\
\hline \hline \multirow{2}{*}{ Campaign 2 } & Displ $_{\text {begining }}$ & 62.5 & 59.1 & 33.5 & 71.2 \\
& Displ $_{\text {end }}$ & 11.7 & 11.9 & 5.1 & 11.6 \\
\hline \multirow{2}{*}{ Campaign 3 } & Displ $_{\text {begining }}$ & 85.2 & 152.9 & 122.7 & 141.6 \\
& Displ $_{\text {end }}$ & 58.4 & 11.4 & 69.6 & 55.3 \\
\hline \multirow{2}{*}{ Campaign 4 } & Displ begining & 135.2 & 135.7 & 136 & 130.1 \\
& Displ $_{\text {end }}$ & 2.5 & 61.3 & 59.4 & 141.3 \\
\hline
\end{tabular}

Table I summarizes the performed test campaigns. Table II

TABLE I

PERFORMED TEST CAMPAIGNS.

\begin{tabular}{l|l|l|l} 
Campaign & Voltage $(V)$ & Frequency $(H z)$ & Air \\
\hline \hline 1 & 8 & $1(86400$ cycles/day $)$ & unfiltered \\
\hline 2 & 8 & $1(86400$ cycles/day $)$ & filtred \\
\hline 3 & 12 & $2.5(216000$ cycles/day $)$ & filtred \\
\hline 4 & 12 & $2.5(216000$ cycles/day $)$ & filtred \\
\hline
\end{tabular}

summarizes the values of the displacement at the beginning and at the end of each campaign of test.

\section{CONCLUSION}

The results of the data acquisition step of a PHM of MEMS application are presented in this paper. First, the specificities of MEMS devices are introduced. After that, the considered MEMS device, which is an elecro-thermally actuated MEMS valve, is presented.

In order to perform accelerated lifetime tests for the MEMS valve and collect monitoring data, an experimental test bed is built. Four test campaigns are performed, where MEMS valves were cycled continuously in the same operating conditions with a periodic square signal. The results of the different tests show that the MEMS valves, which are fabricated with the same micro-fabrication process, do not have the same behavior and the same evolution of degradation in time. The obtained results support the importance of applying the PHM for MEMS devices.

In a future work, the collected monitoring data will be processed to define a degradation model of the MEMS valve. The degradation model can then be used for health assessment and RUL estimation. The results of these latter steps can be used for decision making, which aims at optimizing the utilization of the MEMS, maintaining a good performance as long as possible and avoiding failures.

\section{ACKNOWLEDGMENT}

This work has been supported by the "Région FrancheComté" and the Labex ACTION project (contract ANR-11LABX-0001-01).

\section{REFERENCES}

[1] swisscube, http://swisscube.epfl.ch/, 2009.
[2] M. Lebold and M. Thurston, "Open standards for condition-based maintenance and prognostic systems," in Maintenance and Reliability Conference (MARCON). May, 2001, pp. 6-9.

[3] H. Skima, K. Medjaher, C. Varnier, E. Dedu, and J. Bourgeois, "A hybrid prognostics approach for mems: From real measurements to remaining useful life estimation," Microelectronics Reliability, 2016.

[4] D. Microstaq, http://dmq-us.com/, 2016.

[5] J. Ruan, N. Nolhier, G. Papaioannou, D. Trémouilles, V. Puyal, C. Villeneuve, T. Idda, F. Coccetti, and R. Plana, "Accelerated lifetime test of RF-MEMS switches under ESD stress," Microelectronics Reliability, vol. 49, pp. 1256-1259, 2009.

[6] M. Matmat, K. Koukos, F. Coccetti, T. Idda, A. Marty, C. Escriba, J.Y. Fourniols, and D. Estève, "Life expectancy and characterization of capacitive RF MEMS switches," Microelectronics Reliability, vol. 50, no. 9, pp. 1692-1696, 2010.

[7] R. A. Conant and R. S. Muller, "Cyclic fatigue testing of surfacemicromachined thermal actuators," in ASME Internation Mechanical Engineering Congress and Exposition, 1998, pp. 15-20.

[8] D. M. Tanner, T. B. Parson, A. D. Corwin, J. A. Walraven, J. W. Wittwer, B. L. Boyce, and S. Winzer, "Science-based mems reliability methodology," Microelectronics Reliability, vol. 47, no. 9, pp. 1806-1811, 2007.

[9] D. M. Tanner, J. A. Walraven, M. T. Dugger, T. B. Parson, S. A. Candelaria, M. W. Jenkins, A. D. Corwin, J. A. Ohlhausen, and E. M. Huffman, "Accelerating aging failures in mems devices," in IEEE International Reliability Physics Symposium Proceedings, vol. 43. IEEE; 1999, 2005, p. 317.

[1] 